\title{
Expression of galectin-7 in vulvar lichen sclerosus and its effect on dermal fibroblasts
}

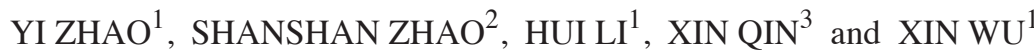 \\ Departments of ${ }^{1}$ Obstetrics and Gynecology, and ${ }^{2}$ Neurology, First Affiliated Hospital of China Medical University; \\ ${ }^{3}$ Department of Physiology, College of Basic Medical Science, China Medical University, \\ Shenyang, Liaoning 110001, P.R. China
}

Received November 26, 2017; Accepted May 2, 2018

DOI: $10.3892 / 01.2018 .8897$

\begin{abstract}
Lichen sclerosus is a chronic and inflammatory disease. Extensive studies have focused on the epidermis, with the dermis or epidermis-dermis receiving less attention. To investigate the role of galectin-7, a keratinocyte protein, in vulvar lichen sclerosus (VLS) and its potential effects on dermal fibroblasts, immunohistochemical staining was performed with VLS tissue samples and normal control samples. The expression of galectin-7 was determined by evaluating the galectin-7 integrated density analysis, and further assessed by western blot analysis. Dermal fibroblasts were isolated from the normal tissue of the female anogenital region following sexual plastic surgery. A cell viability assay was performed on isolated dermal fibroblast cells in the presence or absence of galectin-7. Reverse transcription-quantitative polymerase chain reaction (RT-qPCR) was performed to determine the transcriptional level of collagen I and collagen III in the response to different doses of galectin-7. In the immunohistochemical analysis, galectin-7 demonstrated a significantly elevated level in VLS, compared to control tissues, which was confirmed by western blot analysis. In the analysis of primary dermal fibroblast cells, galectin-7 significantly inhibited the viability rate of fibroblasts in a dose-dependent manner. RT-qPCR data revealed that the transcription level of collagen I and collagen III were positively associated with the galectin-7 treatment concentration. The overexpression of galectin-7 is associated with the progression of VLS in the epidermis, a high concentration of galectin-7 inhibits the viability of the primary vulvar dermal fibroblasts, and stimulates the accumulation of collagen I and collagen III in dermal fibroblast cultures, thus galectin-7 may serve as a drug target during VLS progression.
\end{abstract}

Correspondence to: Professor $\mathrm{Xin} \mathrm{Wu}$, Department of Obstetrics and Gynecology, First Affiliated Hospital of China Medical University, 155 North Nanjing Street, Heping, Shenyang, Liaoning 110001, P.R. China

E-mail: xinwu.1964@aliyun.com

Key words: lichen sclerosus, galectin-7, fibroblast, immunohistochemical, western blot, cell culture

\section{Introduction}

Lichen sclerosus (LS) is a chronic relapsing disease that predominantly affects the female anogenital region. It may occur at any age, but the majority of cases are reported in postmenopausal women (1). It evokes multiple symptoms, including intense itching, pain, burning, stenosis and dysuria, affecting the quality of normal life and sexual activity (1). Currently, there is no cure for LS; instead treatment is primarily aimed at the inhibition of itching, and prevention of scar formation and vulvar anatomical deformities. Previous studies have indicated that numerous factors are involved in LS, including autoimmune disturbance (2), abnormal hormone secretion (3), genetic factors and inflammation (4), although there is no consensus regarding their relative importance. Since the malignant potential of invasive vulvar carcinoma for LS is $\sim 4 \%, \sim 60 \%$ of invasive squamous cell carcinoma are identified in the adjacent site of the LS (5), and thus it is considered as a precancerous lesion. The typical pathological changes of LS include skin epidermis atrophy over keratosis, a dermal layer of connective tissue fibrosis forming a homogeneous zone and lymphocyte infiltration. Genes associated with LS have been identified; these have primarily focused on the dysregulated epidermis, for the hyalinization of collagen fibers in fibroblast hinders further investigation in the superior dermis. The keratinocyte protein, galectin-7, is an apoptosis-associated protein that serves multiple roles in epidermal differentiation, maturation and regeneration (6). Although galectin-7 is not a canonical secreted protein that is transported through the vesicular biosynthetic pathway, it has the ability to reach the cell surface in a fully folded form via an 'unconventional protein secretion' mechanism (7). Thus, we hypothesized that galectin-7 may be secreted by keratinocytes and infiltrate the superior dermis, influencing the cellular activity of the dermal fibroblasts.

\section{Patients and methods}

Patient selection. The present study was approved by the Ethics Committee of China Medical University (Shenyang, China) and written informed consent as obtained from all patients. The present study involved 5 outpatients, 10 in-patients and 10 healthy biopsy tissues obtained from sexual plastic surgery between September 2011 and December 2013. The 
mean age of the 15 patients with VLS was $55.7 \pm 4.3$ years (range, 34-65 years). Patients were diagnosed via the evident VLS morphology and samples were further confirmed by histopathological analysis. All patients had no comorbidities or other medical history and were comparable.

Immunohistochemistry. A total of 15 VLS and 10 normal vulva skin $4 \%$ formalin-fixed (Boster Biological Technology, Pleasanton, CA, USA) at room temperature overnight. The paraffin-embedded $4 \mu \mathrm{m}$ sections of biopsies were examined using an optical microscope (magnification, x200) for galectin-7 expression. Rabbit monoclonal anti-galectin-7 antibody (1:400; cat. no. AB108623; Abcam, Cambridge, UK) was used as the primary antibody at $4^{\circ} \mathrm{C}$ overnight. Alkaline phosphatase-conjugated goat monoclonal anti-rabbit antibody (1:625; cat. no. ZB-2301; OriGene Technologies, Inc., Beijing, China) was used as the secondary antibody at room temperature for $1 \mathrm{~h}$. All immunohistochemical staining were also performed on control biopsy samples. The specificity of the primary antibody was confirmed with the negative signal obtained by substituting normal rabbit serum (ZLI-9023; OriGene Technologies, Inc.) for the primary antibody in the protocol. The pixel of integrated density from 6 sections/sample was measured using ImageJ 1.46 (National Institutes of Health, Bethesda, MD, USA), and a median pixel was calculated.

Western blot analysis. The protein from 10 paired VLS and healthy vulvar tissue samples were extracted using radioimmunoprecipitation assay buffer (P0013B; Beyotime Institute of Biotechnology, Shanghai, China) and quantified using a bicinchoninic acid assay. Loading samples were diluted with protein lysis buffer to produce a final concentration of $5 \mu \mathrm{g} / \mu \mathrm{l}$. SDS-PAGE $(15 \%)$ was performed to separate the protein samples $(14 \mu \mathrm{l})$ by size. Following membrane transfer to a polyvinylidene fluoride membrane (Bio-Rad Laboratories, Inc., Hercules, CA, USA), was blocked with blocking buffer containing 5\% non-fat milk in PBS with Tween-20 at room temperature for $2 \mathrm{~h}$. Blocked membranes were incubated overnight at $4{ }^{\circ} \mathrm{C}$ with a rabbit monoclonal antibody against galectin-7 (1:1,000; cat. no. AB108623; Abcam) and rabbit monoclonal $\beta$-actin (1:1,000; cat. no. SC-47778; Santa Cruz Biotechnology Inc., Dallas, TX, USA) at a dilution of 1:800. Signals were detected using horseradish-peroxidase-anti-rabbit secondary antibodies (1:1,000; cat. no. A0277) and an electrochemiluminescence detection kit (both Beyotime Institute of Biotechnology). Images were captured using a Quantity One v.4.62 software (Bio-Rad Laboratories, Inc.).

Isolation and cultivation of primary dermal fibroblasts. Samples were placed in $70 \%$ ethanol for $10 \mathrm{sec}$ and washed five times with PBS. Then, samples were placed in Dulbecco's modified Eagle medium (DMEM; Thermo Fisher Scientific, Inc., Waltham, MA, USA) with antibiotics. Additional fat tissues were discarded. Subsequently, the samples were cut into 2-3 mm pieces, placed in a petri dish and incubated at $37^{\circ} \mathrm{C}$ in a humidified atmosphere with $5 \% \mathrm{CO}_{2}$ and the medium was replaced every 3 days. Fibroblast outgrowths were harvested by trypsinization and re-seeded (100-110 cells/ml) in a T10 flask in DMEM. Cells were allowed to reach $90 \%$ confluence prior to freezing $\left(-80^{\circ} \mathrm{C}\right)$ or splitting for use in the galectin- 7 experiments.
Cell viability assay. After three passages, fibroblasts were seeded into 96 -well plates at a density of $5 \times 10^{3}$ cells/well. After $24 \mathrm{~h}$, different concentrations of galectin-7 were added $(0.2,0.5$, 1, 2.0 and $5.0 \mu \mathrm{g} / \mathrm{ml}$ ) to the DMEM. Cells were cultivated for another $48 \mathrm{~h}$, then $20 \mu \mathrm{l}$ MTS was added to $100 \mu \mathrm{l}$ medium and the plate was incubated at $37^{\circ} \mathrm{C}$ avoiding exposure to light for $4 \mathrm{~h}$. Optical density values were obtained with a plate reader at $490 \mathrm{~nm}$, data were corrected with blank controls.

Reverse transcription-quantitative polymerase chain reaction $(R T-q P C R)$ analysis. qPCR primers were designed as follows: Collagen I forward, 5'-CCCCCTCCCCAGCCACAA AG-3' and reverse, 5'-TCTTGGTCGGTGGGTGACTCT-3' (product size, $360 \mathrm{bp}$ ); collagen III forward, 5'-CCAAACTCT ATCTGAA-3' and reverse, 5'-GGACTCATAGAATACA-3' (product size, $449 \mathrm{bp}$ ); $\beta$-actin forward, 5'-ATCTGGCACCAC ACTTCTACA-3' and reverse, 5'-GTTTCGTGGATGCCA CAGGCT-3' (product size, $577 \mathrm{bp}$ ).

Briefly, cells were harvested following incubation with different galectin-7 concentrations. According to the results of cell viability assay, the cells were assigned as normal human fibroblasts group (N-HF), low concentration group ( $\leq 1 \mu \mathrm{g} / \mathrm{ml}$, L-galectin) and high concentration group (>1 $\mu \mathrm{g} / \mathrm{ml}, \mathrm{H}$-galectin). The RNA was isolated with TRIzol (Life Technologies; Thermo Fisher Scientific, Inc.) according to the manufacturer's protocol from duplicate or triplicate cell samples. cDNA synthesis was performed on $1 \mu \mathrm{g}$ RNA with SuperScript $^{\mathrm{TM}}$ III First-Strand system (Invitrogen; Thermo Fisher Scientific, Inc.) and oligo(dT) primers, according to the manufacturer's protocols. The cDNA was diluted to a final volume of 200 and $1 \mu \mathrm{l}$ was added to $500 \mathrm{nM}$ of the forward and reverse primers in a final volume of $10 \mu \mathrm{l}$ per PCR reaction. qPCR was performed with $\mathrm{SYBR}^{\circledR}$ Green (Takara Biotechnology Co., Ltd., Dalian, China) under the following conditions: Pre-denature $95^{\circ} \mathrm{C}$ for $1 \mathrm{~min}$; then denature at $95^{\circ} \mathrm{C}$ for $30 \mathrm{sec}$; annealing $44^{\circ} \mathrm{C}$ for $30 \mathrm{sec}$; elongation $72^{\circ} \mathrm{C}$ for 1 min (35 cycles). Melting curve data was collected following amplification. The negative control was loaded with $\mathrm{dd}_{2} \mathrm{O}$. Data were analyzed using the $\Delta \Delta \mathrm{Cq}$ method (8). Charts were plotted using Microsoft Excel 2007 (Microsoft Corporation, Redmond, WA, USA).

Statistical analysis. Statistical analyses were conducted using SPSS v.17.0 software (SPSS Inc., Chicago, IL, USA). Independent samples t-tests were used to compare the expression difference of Gelectin-7 between vulvar normal skin and VLS. Statistical comparisons among groups in the cell viability assay and qPCR were analyzed using one-way analysis of variance with the least significant difference post hoc test. All data are presented as the mean \pm standard error of the mean. $\mathrm{P}<0.05$ was considered to indicate a statistically significant difference.

\section{Results}

High galectin-7 level in VLS tissues. To determine the expression of galectin-7 in the epidermis, immunohistochemical staining of galectin-7 was performed in healthy control biopsy and VLS samples. In the healthy control skin, moderate expression of galectin-7 was detected in the inner part of epidermis, 

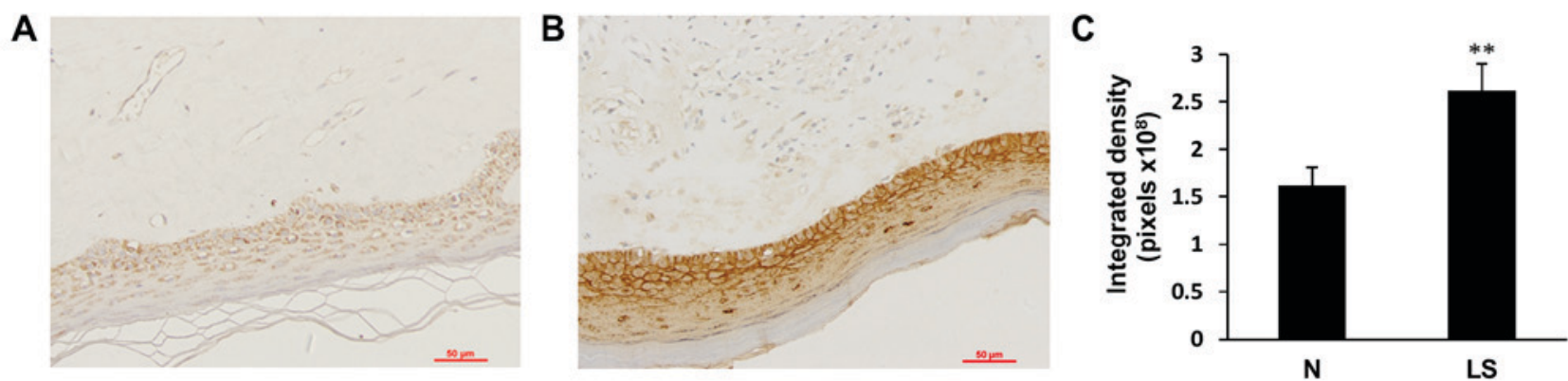

Figure 1. Representative image of immunohistochemical staining of galectin-7 in (A) normal vulvar tissue and (B) vulvar lichen sclerosus (magnification, $\mathrm{x} 200)$. (C) galectin-7 was significantly elevated in the vulvar lichen sclerosus samples compared with the normal vulvar tissues $\left({ }^{* *} \mathrm{P}<0.01\right)$. Date was presented as the mean \pm standard deviation.

with an even distribution in the nucleus and cytoplasm. In contrast, VLS tissue exhibited significantly elevated immune expression of galectin-7 in the superficial epidermis (Fig. 1; $\mathrm{P}<0.01)$. To further confirm the immunohistochemical staining results, the protein content was extracted from tissues and western blotting was performed with the galectin-7 antibody. The results demonstrated $>5$-fold upregulation in galectin-7 expression in VLS tissue compared with healthy tissue (Fig. 2; $\mathrm{P}<0.01)$. These data indicated a positive association between galectin-7 expression and VLS.

Galectin-7 inhibits the viability of primary dermal fibroblast cells. To determine whether galectin-7 influences vulvar dermis fibroblasts, primary dermal fibroblast cells were isolated from healthy control biopsy tissue. Phase contrast microscopy demonstrated spindle shaped fibroblasts, whereby the cells were bipolar and refractile, with enlarged nuclei (Fig. 3A and B). To confirm that the cells were fibroblasts, the typical mesoderm marker Vimentin, which is expressed in fibroblasts was used for staining (9). It was observed that all the isolated fibroblast cells exhibited Vimentin expression (Fig. 3C and D). Whether galectin-7 serves a role in the growth rate of the isolated primary dermal fibroblasts was then investigated. There were significant overall group effects in the result of the MTS cell viability assay $\left[\mathrm{F}_{(5,12)}=7.631 ; \mathrm{P}=0.002\right]$. It revealed that galectin-7 exerted a significantly inhibitory effect on fibroblasts at concentrations $>1 \mu \mathrm{g} / \mathrm{ml}$. Compared with that of untreated fibroblasts, fibroblast viability was significantly impaired at the concentrations of $2 \mu \mathrm{g} / \mathrm{ml}(\mathrm{P}<0.05)$ and $5 \mu \mathrm{g} / \mathrm{ml}$ $(\mathrm{P}<0.01)(0.82 \pm 0.03$ vs. $0.63 \pm 0.81$ and $0.60 \pm 0.11$, respectively), indicating that galectin-7 serves a negative role on the growth of primary dermal fibroblasts (Fig. 4).

Galectin-7 regulates Collagen I and collagen III at transcriptional level. A typical feature of VLS is the accumulation and dis-organization of collagen I and collagen III in the dermal fibroblasts (10). We hypothesized that galectin-7 may contribute to VLS through regulating the dermal fibroblast function and influencing collagen levels. Isolated primary dermal fibroblasts were seeded in the presence of galectin-7 and a qPCR analysis was performed to determine the transcriptional level of collagen I and collagen III. The results demonstrated that the levels of collagen $\mathrm{I}\left[\mathrm{F}_{(2.6)}=6.267 ; \mathrm{P}=0.034\right]$ and collagen III $\left[\mathrm{F}_{(2.6)}=26.669 ; \mathrm{P}=0.001\right]$ were significantly elevated following the administration of galectin-7 in a dose-dependent manner (Fig. 5). It would be interesting to explore in the future whether the accumulated collagens are irregularly distributed in the cytoplasm of fibroblasts, and whether they contribute to the hyalinization encountered in VLS.

\section{Discussion}

In the current study, it was observed that galectin-7 serves important roles in primary dermal fibroblasts, including an inhibitory role on their growth rate, as well as a promoter role on the transcription of collagen I and collagen III. The increased expression of galectin-7 in patients with VLS significantly influenced the viability of fibroblasts.

Members of the galectin family are recognized for their ability to bind $\beta$-galactosides via a highly conserved carbohydrate recognition domain. They serve an important role in several physiological processes, including embryonic development, intercellular adhesion, host-pathogen interactions, cell migration and the immune response (11). Galectin-7 belongs to the galectin family and was initially described as a marker of epithelial differentiation, due to its expression in the stratified epithelium of various tissues. It is induced by $\mathrm{p} 53$, thus it is also known as p53-induced gene 1 (12). The induction of galectin-7 triggers the release of cytochrome $c$ and increases the activity of JUN N-terminal kinase (JNK), triggering programmed apoptosis (13), which provides evidence of the inhibitory effect on cell viability. The results of the present study demonstrated that galectin-7 was significantly upregulated in VLS tissue from patients compared with healthy tissue, indicating that a high level of galectin-7 may increase the apoptosis rate of epidermal cells and inhibit their viability, leading to the shrinking and loss of epidermal tissue. There is evidence that the epidermis of extracellular superoxide dismutase (EC-SOD) transgenic mice produces more galectin-7 compared with wild type animals, and furthermore the epidermis of EC-SOD transgenic mice is thinner compared with that in their wild type counterparts (14). Transgenic mice were developed specifically overexpressing galectin-7 to aid in research into the basal epidermal keratinocytes. It was reported that an excess of galectin-7 causes a destabilization of the adherens junctions associated with defects in epidermal repair (15). Another study demonstrated that galectin-7 is highly expressed in the epidermis of patients with actinic keratosis, and that galectin-7 upregulates the apoptosis of the epidermis via $\mathrm{T}$ lymphocytes (16). The galectin-7 gene was reported to be upregulated 
A

Galectin-7

$\mathbf{N}$

LS

$\beta$-actin
B

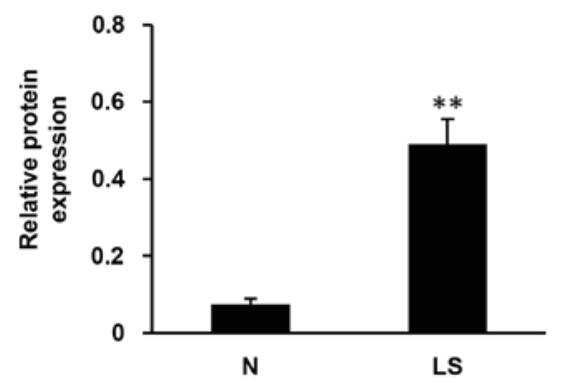

Figure 2. Expression levels of galectin-7 were analyzed using western blot analysis. (A) Expression of galectin-7 in 10 pairs of lichen sclerosus (LS) and normal vulvar tissues (N). $\beta$-actin was used as an internal standard. (B) Galectin-7 was significantly elevated in the VLS samples compared to the normal vulvar tissues ( $\left.{ }^{* *} \mathrm{P}<0.01\right)$. VLS, vulvar lichen sclerosus; $\mathrm{N}$, normal vulvar tissues; LS, lichen sclerosus. Data was presented as the mean \pm standard deviation.
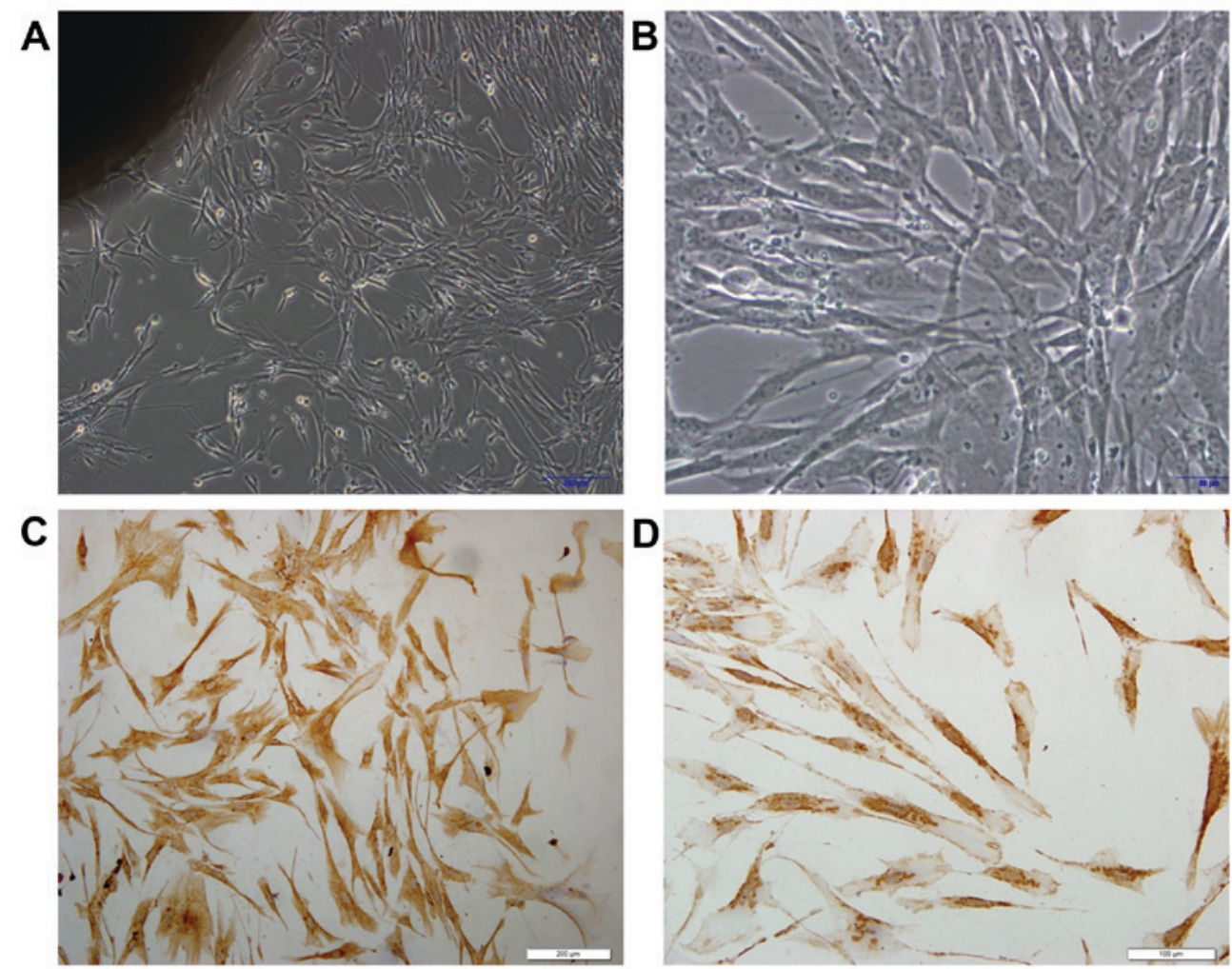

Figure 3. Fibroblasts in primary culture and verification. Fibroblast primary culture at (A) magnification, x100 and (B) x200. Vimentin immunocytochemistry images at (C) magnification, x200 and (D) x400, demonstrating that the cells were positive for vimentin, and thus fibroblasts.

by 8 -fold in bronchial epithelial cells from asthmatic children following RSV infection in vitro, compared with tissues from the healthy control patients, indicating that this protein may be associated with bronchial epithelial cell apoptosis in asthma (17). These findings suggest that the overexpression of galectin-7 is associated with VLS epidermal atrophy.

In our previous study, it was demonstrated that galectin-7 was downregulated in the early stage of vulvar squamous cell carcinoma (18). Since it is a pro-apoptosis protein, this may be associated with the progression of malignancy. Other reports have revealed a high expression of galectin-7 in certain cancer cell lines, including in breast cancer (19), cervical cancer (20), and late and poorly differentiated vulvar squamous cell carcinoma (18). Galectin-7 has also been associated with a poor prognosis in ovarian cancer (21). In summary, the role of galectin-7 in apoptosis may be organ- or tissue-dependent, and may be associated with the methylation pattern of galectin-7 itself $(22,23)$.

Due to the multifunctional of the galectin family, its sub-cellular localization has been extensively studied. Based on the fact that galectins are able to be detected in intracellular and extracellular locations, as well as in the plasma of patients with tumors, recombinant galectins have been used widely in various in vitro models (11). All lectins, whether dimers or oligomers, bind to cell surface receptors, including growth factor receptors and integrins $(24,25)$. The results of the immunohistochemistry assay in the present study revealed that galectin-7 was expressed exclusively in the epidermis. Galectin-7 is specifically synthesized and secreted by keratinized epithelial cells. Non-keratinizing cells can only be obtained through membrane surface receptors (12). In the immunohistochemistry experiments in the present study, galectin-7 was not detected 


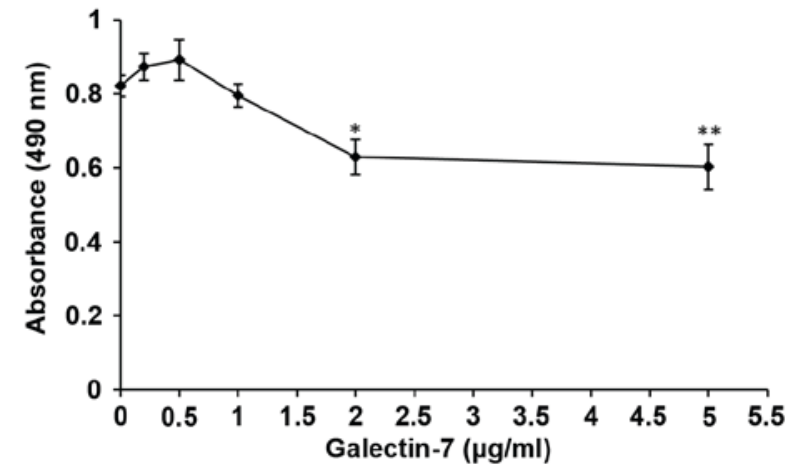

Figure 4. Effect of different concentrations of galectin-7 on the viability of human skin fibroblasts. ${ }^{*} \mathrm{P}<0.05,{ }^{* *} \mathrm{P}<0.01$ vs. the point at $0 \mu \mathrm{g} / \mathrm{ml}$. Data was presented as the mean \pm standard deviation.

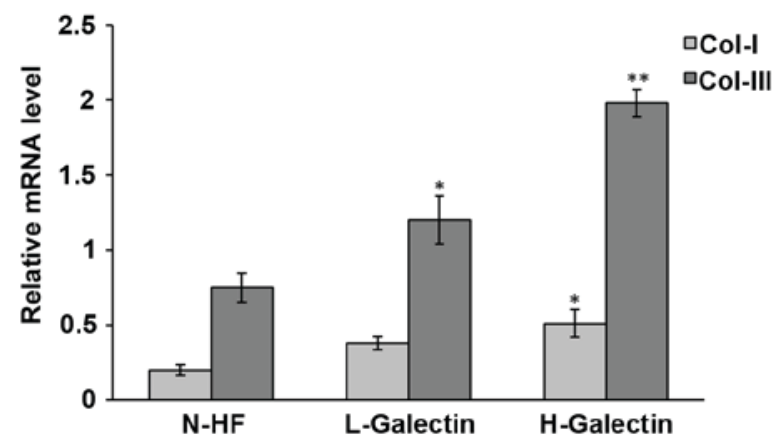

Figure 5. Expression levels of type I and II procollagen mRNA in fibroblasts cultured with different concentrations of galectin-7. " $\mathrm{P}<0.05$, ${ }^{* *} \mathrm{P}<0.01$ vs. N-HF. N-HF, normal human fibroblasts; L-galectin concentration, $\leq 1.0 \mu \mathrm{g} / \mathrm{ml}$; H-galectin concentration, $>1.0 \mu \mathrm{g} / \mathrm{ml}$. Data was presented as the mean \pm standard deviation.

in the dermis. It was hypothesized that galectin-7 formed in the epidermis can reach the dermis via paracrine and bind to the surface receptor of dermal fibroblast cell membrane, which affects cell function. Therefore, in subsequent cell experiments, recombinant galectin-7 was added to the culture medium to detect changes in collagen fibers. A previous study reported that recombinant galectin-3 binds to the glycol-receptor and stimulates the expression of matrix metalloproteinase 9 (26). We hypothesized that the elevated galectin-7 expression in the VLS epidermis may be released to the dermal part of the skin and bind to fibroblasts, and thus, galectin-7 may modulate the function of dermal fibroblasts.

In the dermis layer, dermal fibroblasts generate connective tissue allowing the skin to recover from injury. One of the primary functions of dermal fibroblasts is to produce proteins which form the extracellular matrix (27); among these proteins, collagen I and collagen III are the main collagens generated (28). To the best of our knowledge, no suitable animal models for Lichen sclerosus have been produced previously (29). Therefore, primary dermal fibroblasts isolated from the healthy control tissues through biopsy were cultured to mimic the in vivo progression of VLS. As revealed by the results of the present study, a high concentration of galectin- 7 (>1 $\mu \mathrm{g} / \mathrm{ml})$ significantly inhibited the viability of fibroblasts. Notably, exposure to a low dose $(<1 \mu \mathrm{g} / \mathrm{ml})$ slightly promoted the viability of fibroblasts, although this was not significant. It is not known whether this is associated with different levels of galectin-7 expression in the epidermis. Due to the characteristics of pathological tissues, it is difficult to perform further research, and there have been no literature regarding any change in the number of dermal cells in VLS.

In the present study, the expression of collagens and its association with galectin-7 in primary dermal fibroblasts were also analyzed. Collagen I and collagen III, the primary collagens generated by dermal fibroblasts, were upregulated by galectin-7 in a dose-dependent manner, suggesting that galectin-7 may be an essential regulator for the hyalinization mediated by fibroblasts in VLS. Thus, galectin-7 has the potential of being a target in VLS therapy. Galectin-7 might positively regulate the collagen expression through the JNK pathway since the apoptotic role of Galcetin-7 is mediated by accelerating the release of cytochrome $\mathrm{C}$ and the upregulation of JNK. Hashimoto et al (30) reported that tumor growth factor- $\beta$ promoted the transdifferentiation of fibroblasts into myofibroblasts through JNK and that also led to the production of extracellular matrix proteins, leading to pulmonary fibrosis (30). In VLS skin, the hyalinized collagen is found below the epithelium. Whether galectin-7 has a role in the irregular distribution of collagen fibers still needs to be clarified. Certain data have indicated that galectin-7 induces the viability of $\mathrm{T}$ cells, primarily the cluster of differentiation $8+$ sub-population (31), and possibly function as an accelerant of T-cell responses (32). A previous study described the autoimmune phenotype in VLS, including high levels of Th1-specific cytokines as well as a dense infiltration of T cells (33). All these data suggest that galectin-7 may serve a role in the elevated immune response encountered in VLS.

In conclusion, the present study identified that the expression of galectin-7 was significantly upregulated in VLS tissues. In addition, galectin-7 significantly inhibited the viability of dermal fibroblasts and stimulated the production of collagen, thus galectin-7 may be a potential drug target for the treatment of patients with VLS.

\section{Acknowledgements}

This manuscript has been edited by the professional English writing editor, Dr. Ewen MacDonald from the University of Eastern Finland.

\section{Funding}

The present study was supported by the National Natural Science Foundation of China (grant nos. 30973190 and 81400202).

\section{Availability of data and materials}

All data generated or analyzed during this study are included in this published article.

\section{Authors' contributions}

YZ drafted the manuscript and performed the immunohistochemical and western blot analysis. SZ conducted the 
statistical analyses. HL performed the PCR. XQ performed the cell culturing. XW has provided conceptualization and approved the final version to be published. All authors made substantial contributions to this manuscript.

\section{Ethics approval and consent to participate}

The present study was approved by the Ethics Committee of China Medical University (Shenyang, China) and written informed consent as obtained from all patients.

\section{Consent for publication}

Written informed consents from all patients were obtained. There is no identifying information in the article.

\section{Competing interests}

The authors declare that they have no competing interests.

\section{References}

1. Val I and Almeida G: An overview of lichen sclerosus. Clin Obstet Gynecol 48: 808-817, 2005.

2. Regauer S, Reich $\mathrm{O}$ and Beham-Schmid C: Monoclonal gamma-T-cell receptor rearrangement in vulvar lichen sclerosus and squamous cell carcinomas. Am J Pathol 160: 1035-1045, 2002.

3. Birenbaum DL and Young RC: High prevalence of thyroid disease in patients with lichen sclerosus. J Reprod Med 52: 28-30, 2007.

4. Hantschmann P, Sterzer S, Jeschke U and Friese K: P53 expression in vulvar carcinoma, vulvar intraepithelial neoplasia, squamous cell hyperplasia and lichen sclerosus. Anticancer Res 25: 1739-1745, 2005.

5. Pugliese JM, Morey AF and Peterson AC: Lichen sclerosus: Review of the literature and current recommendations for management. J Urol 178: 2268-2276, 2007.

6. Fujimoto N, Asano C, Ono K and Tajima S: Verruciform Xanthoma results from epidermal apoptosis with galectin-7 overexpression. J Eur Acad Dermatol Venereol 27: 922-923, 2013.

7. Cummings RD and Liu FT: Galectins. Cold Spring Harbor Laboratory Press 33, 2009.

8. Livak KJ and Schmittgen TD: Analysis of relative gene expression data using real-time quantitative PCR and the 2(-Delta Delta C(T)) method. Methods 25: 402-408, 2001.

9. Nishioka M, Venkatesan N, Dessalle K, Mogas A, Kyoh S, Lin TY, Nair P, Baglole CJ, Eidelman DH, Ludwig MS and Hamid Q: Fibroblast-epithelial cell interactions drive epithelial-mesenchymal transition differently in cells from normal and COPD patients. Respir Res 16: 72, 2015.

10. Godoy CA, Teodoro WR, Velosa AP, Garippo AL, Eher EM, Parra ER, Sotto MN and Capelozzi VL: Unusual remodeling of the hyalinization band in vulval lichen sclerosus by type $\mathrm{V}$ collagen and ECM 1 protein. Clinics (Sao Paulo) 70: 356-362, 2015.

11. Di Lella S, Sundblad V, Cerliani JP, Guardia CM, Estrin DA, Vasta GR and Rabinovich GA: When galectins recognize glycans: From biochemistry to physiology and back again. Biochemistry 50: 7842-7857, 2011.

12. Polyak K, Xia Y, Zweier JL, Kinzler KW and Vogelstein B: A model for p53-induced apoptosis. Nature 389: 300-305, 1997

13. Barkan B, Cox AD and Kloog Y: Ras inhibition boosts galectin-7 at the expense of galectin-1 to sensitize cells to apoptosis. Oncotarget 4: 256-268, 2013.

14. Lee JS, Lee Y, Jeon B, Jeon Y, Yoo H and Kim TY: EC-SOD induces apoptosis through COX-2 and galectin-7 in the epidermis. J Dermatol Sci 65: 126-133, 2012.

15. Gendronneau G, Sanii S, Dang T, Deshayes F, Delacour D, Pichard E, Advedissian T, Sidhu SS, Viguier M, Magnaldo T and Poirier F: Overexpression of galectin-7 in mouse epidermis leads to loss of cell junctions and defective skin repair. PLoS One 10: e0119031, 2015.
16. Yamaguchi T, Hiromasa K, Kabashima-Kubo R, Yoshioka M and Nakamura M: Galectin-7, induced by cis-urocanic acid and ultraviolet B irradiation, down-modulates cytokine production by T lymphocytes. Exp Dermatol 22: 840-842, 2013.

17. Yin GQ, Zhao SY, Guo SP, Zhao YH, Liu XC and Jiang ZF: Galectin-7 is associated with bronchial epithelial cell apoptosis in asthmatic children. Zhonghua Er Ke Za Zhi 44: 523-526, 2006 (In Chinese).

18. Jiang Y, Tian R, Yu S, Zhao YI, Chen Y, Li H, Qiao Y and Wu X: Clinical significance of galectin-7 in vulvar squamous cell carcinoma. Oncol Lett 10: 3826-3831, 2015.

19. Grosset AA, Poirier F, Gaboury L and St-Pierre Y: Galectin-7 expression potentiates her-2-positive phenotype in breast cancer. PLoS One 11: e0166731, 2016.

20. Higareda-Almaraz JC, Ruiz-Moreno JS, Klimentova J, Barbieri D, Salvador-Gallego R, Ly R, Valtierra-Gutierrez IA, Dinsart C, Rabinovich GA, Stulik J, et al: Systems-level effects of ectopic galectin-7 reconstitution in cervical cancer and its microenvironment. BMC Cancer 16: 680, 2016.

21. Kim HJ, Jeon HK, Lee JK, Sung CO, Do IG, Choi CH, Kim TJ, Kim BG, Bae DS and Lee JW: Clinical significance of galectin-7 in epithelial ovarian cancer. Anticancer Res 33: 1555-1561, 2013.

22. Demers M, Couillard J, Giglia-Mari G, Magnaldo T and St-Pierre Y: Increased galectin-7 gene expression in lymphoma cells is under the control of DNA methylation. Biochem Biophys Res Commun 387: 425-429, 2009.

23. Kim SJ, Hwang JA, Ro JY, Lee YS and Chun KH: Galectin-7 is epigenetically-regulated tumor suppressor in gastric cancer. Oncotarget 4: 1461-1471, 2013.

24. Rabinovich GA, Toscano MA, Jackson SS and Vasta GR: Functions of cell surface galectin-glycoprotein lattices. Curr Opin Struct Biol 17: 513-520, 2007.

25. Garner OB and Baum LG: Galectin-glycan lattices regulate cell-surface glycoprotein organization and signalling. Biochem Soc Trans 36: 1472-1477, 2008.

26. Dange MC, Agarwal AK and Kalraiya RD: Extracellular galectin-3 induces MMP9 expression by activating p38 MAPK pathway via lysosome-associated membrane protein-1 (LAMP1). Mol Cell Biochem 404: 79-86, 2015.

27. Quan T, Little E, Quan H, Qin Z, Voorhees JJ and Fisher GJ: Elevated matrix metalloproteinases and collagen fragmentation in photodamaged human skin: Impact of altered extracellular matrix microenvironment on dermal fibroblast function. J Invest Dermatol 133: 1362-1366, 2013.

28. Lochner K, Gaemlich A, Sudel KM, Südel KM, Venzke K, Moll I, Knott A, Stäb F, Wenck H, Döring O, et al: Expression of decorin and collagens I and III in different layers of human skin in vivo: A laser capture microdissection study. Biogerontology 8: 269-282, 2007.

29. Canady J, Karrer S, Fleck M and Bosserhoff AK: Fibrosing connective tissue disorders of the skin: Molecular similarities and distinctions. J Dermatol Sci 70: 151-158, 2013.

30. Hashimoto S, Gon Y, Takeshita I, Matsumoto K, Maruoka S and Horie T: Transforming growth Factor-beta1 induces phenotypic modulation of human lung fibroblasts to myofibroblast through a c-Jun-NH2-terminal kinase-dependent pathway. Am J Respir Crit Care Med 163: 152-157, 2001.

31. Rossi NE, Reiné J, Pineda-Lezamit M, Pulgar M, Meza NW, Swamy M, Risueno R, Schamel WW, Bonay P, Fernández-Malavé E and Regueiro JR: Differential antibody binding to the surface alphabetaTCR.CD3 complex of CD4+ and CD8+ T lymphocytes is conserved in mammals and associated with differential glycosylation. Int Immunol 20: 1247-1258, 2008.

32. Luo Z, Ji Y, Zhou H, Huang X, Fang J, Guo H, Pan T and Chen ZK: Galectin-7 in cardiac allografts in mice: Increased expression compared with isografts and localization in infiltrating lymphocytes and vascular endothelial cells. Transplant Proc 45: 630-634, 2013.

33. Terlou A, Santegoets LA, van der Meijden WI, Heijmans-Antonissen C, Swagemakers SM, van der Spek PJ, Ewing PC, van Beurden M, Helmerhorst TJ and Blok LJ: An autoimmune phenotype in vulvar lichen sclerosus and lichen planus: A Th1 response and high levels of microRNA-155. J Invest Dermatol 132: 658-666, 2012. 